\title{
Non-Hodgkin Lymphoma of the Liver: A US Population-based Analysis
}

\author{
Mohamed Abd El-Fattah* \\ Department of Internal Medicine, Faculty of Medicine, Suez Canal University, Ismailia, Egypt
}

\begin{abstract}
Background and Aims: Non-Hodgkin lymphoma (NHL) of the liver is a rare lymphoid malignancy, accounting for less than $1 \%$ of extranodal lymphomas. Methods: I conducted an analysis of the U.S Surveillance, Epidemiology, and End Results (SEER) database to evaluate the histological subtypes and the survival outcomes of 785 cases with hepatic NHL between 1973 and 2012. Results: There were 785 of 312 459 cases with NHL had a first primary hepatic NHL $(0.25 \%)$. Of the total 785 cases, the median age at diagnosis was 61 years (range 3-95 years) and male-female ratio of 1.7:1. The most common subtype was diffuse large B cell lymphoma $(63.2 \%)$. In all patients, the median overall survival (OS) was 33 months (95\%CI, 22-48 months). The 5-year OS rate for indolent B-cell NHLs was $62 \%$, compared with $44 \%$ for an aggressive B-cell NHLs and $42 \%$ for T-cell NHLs. The median OS improved from 19 months in patients diagnosed in a period 1996-2000 to 60 months when diagnosed between 2006 and $2012(p<.001)$. In a multivariable Cox regression analysis, the age $\geq 80$ years (adjusted hazard ratio [aHR] 3.21, $p<.001)$, male gender (aHR 1.26, $p=.02$ ), Black race (aHR, $1.70, p<.001$ ), and T-cell NHL variants (aHR 1.73, $p=.03$ ) were unfavourable prognostic factors. Conclusion: NHL of the liver comprises about $0.3 \%$ of all NHLs and survival was improved in the recent calendar period.
\end{abstract}

Citation of this article: El-Fattah MA. Non-Hodgkin lymphoma of the liver: a US population-based analysis. J Clin Transl Hepatol 2017;5(2):83-91. doi: 10.14218/JCTH.2017.00015.

\section{Introduction}

Non-Hodgkin lymphoma ( $\mathrm{NHL})$ is the sixth leading cause of new cancer cases among men and the fifth among women, accounting for $3 \%$ to $4 \%$ of cancer-related deaths in the United States. ${ }^{1}$ Approximately $25 \%$ to $40 \%$ of $\mathrm{NHL}$ patients present with an extranodal lymphoma. ${ }^{2}$ Although

Keywords: Non-Hodgkin lymphoma; Liver; Primary hepatic lymphoma; Hepatic neoplasms.

Abbreviations: NHL, non-Hodgkin lymphoma; PHL, primary hepatic lymphoma; $\mathrm{HIV}$, human immunodeficiency virus; DLBCL, diffuse large B-cell lymphoma; $\mathrm{HCV}$, hepatitis $C$ virus; HBV, hepatitis B virus; EBV, Epstein-Barr virus; MRI, magnetic resonance imaging; OS, overall survival; $\mathrm{HEL}$, hepatic lymphoma; $\mathrm{MZL}$, marginal zone B cell lymphoma; SLL, small B cell lymphocytic lymphoma; HTLV-1, human T cell leukemia virus-1; MALT, mucosa-associated lymphoid tissue.

Received: 1 March 2017; Revised: 23 March 2017; Accepted: 3 April 2017

*Correspondence to: Mohamed Abd El-Fattah, Department of Internal Medicine, Faculty of Medicine, Suez Canal University, Ring Road, Ismailia City, Ismailia 41522, Egypt. Tel: +20-122-759-7912, +20-64-3215166, E-mail: mafattah3000@yahoo. com liver contains lymphoid tissue, host factors seem to make the liver a poor environment for the development of malignant lymphomas. NHL is more likely than Hodgkin lymphoma to have hepatic involvement. ${ }^{3}$ The prevalence of liver involvement by $\mathrm{NHL}$ is reported to be $15 \%$ to $30 \%$, and more than $50 \%$ in necropsy studies. ${ }^{3-8}$

Primary hepatic lymphoma $(\mathrm{PHL})$ is a lymphoma limited to the liver or having major liver involvement without evidence of extrahepatic involvement (e.g., no spleen, lymph nodes, bone marrow, peripheral blood, or other lymphoid structures) for at least 6 months. ${ }^{7} \mathrm{PHL}$ represents $0.4 \%$ of extranodal NHLs and $0.016 \%$ of all NHLs. ${ }^{7,8}$ Based on liver infiltration, PHL can be subdivided into uninodular (39-42\%), multinodular (50-55\%), and diffuse (6-8\%) types. ${ }^{6,9}$ Diffuse liver involvement of PHL is usually observed in immuno-compromised patients, ${ }^{10}$ such as human immunodeficiency virus (HIV) or liver diseases. ${ }^{11}$ Among 205 liver biopsies with lymphoma, $45 \%$ was diffuse large B cell lymphoma (DLBCL), and $12 \%$ was T cell lymphoma. ${ }^{12}$

Chronic antigen stimulation by viral infection (HIV, hepatitis $C$ virus (HCV), hepatitis B virus (HBV) and Epstein-Barr virus (EBV), liver cirrhosis, immunosuppressive therapy and autoimmune disease are implied to have an etiological relevance to the development of $\mathrm{PHL}{ }^{8} \mathrm{HCV}$ is found in $10 \%$ to $60 \%$ of patients with $\mathrm{PHL}, 6,9,13,14$ with geographic variations, and these patients have aggressive histological subtypes. ${ }^{9,15}$ Most PHL of HCV-positive patients were of B cell origin, and T cell type PHL has been rarely reported. ${ }^{15}$ It seems that $\mathrm{PHL}$ outcomes are not affected by presence of HCV infection ${ }^{6}$ and regress with $\mathrm{HCV}$ eradication. ${ }^{16}$ Furthermore, HIV was reported in $40 \%$ to $75 \%$ of $\mathrm{PHL}$ cases, ${ }^{10,14}$ and these patients have a worse prognosis. ${ }^{11}$

PHL most commonly affects men during their fifth decade of life, and has a male-to-female ratio of $2-3: 1.3,8,17$ Liver biopsy is the most valuable tool for diagnosis. ${ }^{10,14}$ Clinical presentation of PHL is nonspecific and includes such symptoms as fever, loss of weight, night sweats, abdominal pain, jaundice and hepatomegaly. Incidental identification has been documented in $10 \%$ of $\mathrm{PHL}$ cases. ${ }^{18}$ Acute liver failure reportedly accounts for $4.5 \%$ of $\mathrm{PHL}$ presentations, ${ }^{8}$ and about $3 \%$ of reported acute liver failure was related to hepatic lymphoma, ${ }^{19}$ notably of diffuse pattern. ${ }^{20}$ Most cases of acute liver failure from lymphoma are diagnosed on autopsy, with an average survival of 11 days from diagnosis. ${ }^{21}$ PHL patients have abnormal liver function tests, with elevation of lactate dehydrogenase and alkaline phosphatase. Alpha-fetoprotein and carcinoembryonic antigen are normal in almost all cases, and hypercalcemia was observed in $40 \%$ of cases, ${ }^{6}$ being related to release of calcitriol by malignant lymphoma cells. ${ }^{22}$ 
Radiologically, PHL lesions on ultrasound are hypoechoic, and on computed tomography are hypoattenuating with intravenous rim enhancement. ${ }^{23,24}$ On magnetic resonance imaging (MRI), the lesions show hypointensity on T1-weighted images and hyperintensity on T2-weighted images. ${ }^{24}$

Approximately $80 \%$ of the reported cases with PHL have been of the $B$ cell type (mainly DLBCL), whereas the remaining cases have been of the $T$ cell type. ${ }^{5,17}$ Patients with hepatic DLBCL tend to be HCV-positive and have a diffuse liver infiltration with a poor prognosis. ${ }^{25}$ T cell lymphoma of the liver accounted for $5-10 \%$ of $\mathrm{PHL}$ patients, ${ }^{3}$ and these patients have shown an aggressive clinical course, ${ }^{26}$ and are mainly of the Asian population. ${ }^{27}$

Therapeutic management of $\mathrm{PHL}$ is based on surgery, chemotherapy and radiotherapy. However, $14 \%$ of cases are inappropriate for therapy due to comorbidity or poor performance. ${ }^{14}$ With chemotherapy, the reported survival ranges from 3.7 to 30 months, ${ }^{8}$ and liver transplantation is favorable. ${ }^{20}$ The 5 -year overall survival (OS) of treated patients with $\mathrm{PHL}^{6}$ is comparable to that of hepatocellular carcinoma patients who undergo liver transplantation. ${ }^{28}$ Prognosis of PHL depends on NHL subtype, type of liver involvement (nodular or diffuse) ${ }^{11}$ therapeutic modalities (chemotherapy, surgery or radiotherapy), ${ }^{18}$ HIV status ${ }^{5}$ and liver disease. ${ }^{9}$

The aim of this retrospective study was to assess the clinical characteristics, subtypes and outcomes of NHL affecting the liver. To date, fewer than $400 \mathrm{PHL}$ cases have been reported in the worldwide literature $3,7,8,18,21,25,29-31$ and large case series..$^{6,9,10,14,32}$

\section{Methods}

\section{Data source}

The Surveillance Epidemiology and End Results (SEER) program of the U.S National Cancer Institute collects and publishes cancer incidence and survival data from population-based cancer registries covering approximately $30 \%$ of the US population (www.seer.cancer.gov). The SEER database includes cancer registries in the following areas; Atlanta, Connecticut, Detroit, Hawaii, Iowa, New Mexico, San Francisco-Oakland, Seattle-Puget Sound, Utah, Los Angeles, San Jose-Monterey, Rural Georgia, the Alaska Native Tumor Registry, Greater California, Kentucky, Louisiana, New Jersey, and Greater Georgia.

\section{Study population}

Hepatic NHL in the SEER cancer registry (1973 to 2012) was defined by cancer diagnosis in anatomic site of liver by International Classification of Diseases, 3rd edition codes (ICD-O-3 code, C22.0) and NHL morphologies (9590-9595 and 96709723). For this study, I used the same variable selection approach of O'Neill et al. ${ }^{33}$ for NHL of the central nervous system in the SEER database study. As shown in Fig. 1, I restricted analysis to the patients who had microscopic confirmation of their disease (tissue histology or cytology). In an attempt to assure that only first primary NHLs were included in the analysis, I excluded patients who had a prior, or a concurrent diagnosis of other cancers. I also excluded patients diagnosed by autopsy or death certificate, and who had a survival time of 0 months. The few patients who had incomplete data regarding radiation or surgery were not included in the analysis. The final cohort included
(Fig. 1) 785 patients with hepatic lymphoma (HEL) grouped into categories according to cell origin and clinical aggressiveness as follows: (1) aggressive B cell NHLs (DLBCL and Burkitt's lymphoma); (2) Indolent B cell NHLs (follicular lymphoma; small B cell lymphocytic lymphoma and marginal zone B cell lymphoma), (3) T cell NHLs (mature T cell lymphoma and anaplastic large cell lymphoma, $\mathrm{T}$ cell and null cell type); (4) NHL- not otherwise specified [NHL-NOS]; and (5) other rare subtypes. Age was categorized into 5 age groups of $<50,50-59,60-69,70-79$, and $\geq 80$ years. Race was categorized as White, Black, Asian and Others. The cohort was divided into 4 according to the year of diagnosis (1973-1995, 1996-2000, 2001-2005, and 2006-2012). HIV-related deaths were identified in the SEER by variable 'cause of death to SEER site recode' (code 50040).

\section{Statistical analysis}

The clinical and demographic characteristics were expressed as proportion (\%) and frequency $(n)$ for categorical variables, or as median and range for continuous variables. The primary endpoint of the study was OS, which was defined as the interval between the date of diagnosis of HEL to the date of death from any cause (follow-up to obtain vital status) or

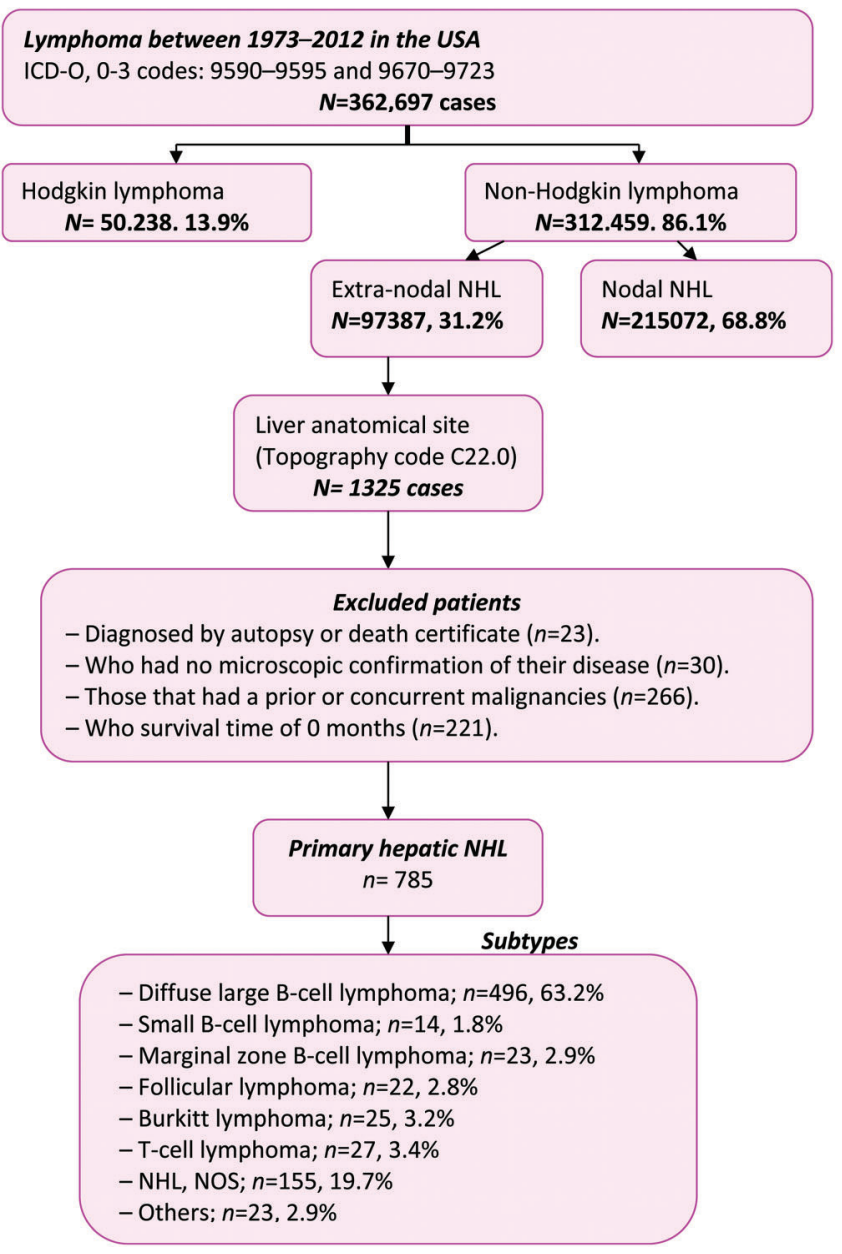

Fig. 1. Flow diagram of patient selection within the SEER database during 1973-2012.

Abbreviation: ICD, International Classification of Diseases for Oncology. 
El-Fattah M.A.: Outcomes of hepatic non-Hodgkin lymphoma

Table 1. Patient characteristics by histologic subtype

\begin{tabular}{|c|c|c|c|c|c|}
\hline \multirow[b]{2}{*}{ Histology } & \multirow[b]{2}{*}{$n(\%)$} & \multirow[b]{2}{*}{ Median age, years (Range) } & \multirow[b]{2}{*}{ Male, $n(\%)$} & \multicolumn{2}{|c|}{ Overall survival } \\
\hline & & & & Median OS & 5-year OS \\
\hline All patients & $785(100.0)$ & $61(3-95)$ & $504(64.2)$ & 33.0 & 44 \\
\hline DLBCL & $496(63.2)$ & $62(3-95)$ & $328(66.1)$ & 28.1 & 43 \\
\hline SLL & $14(1.8)$ & $67(41-81)$ & $10(71.4)$ & 53 & 42 \\
\hline MZL & $23(2.9)$ & $68(44-87)$ & $11(47.8)$ & 82.9 & 60 \\
\hline Follicular lymphoma & $22(2.8)$ & $64.5(41-81)$ & $9(40.9)$ & NR & 84 \\
\hline Burkitt's lymphoma & $25(3.2)$ & $36(5-87)$ & $19(76.0)$ & NR & 55 \\
\hline T cell lymphoma & $27(3.4)$ & $52(25-90)$ & $21(77.8)$ & 8.3 & 42 \\
\hline NHL-NOS & 155 (19.7) & $58(11-91)$ & $96(61.9)$ & 21.2 & 43 \\
\hline Others & $23(2.9)$ & $60(21-88)$ & $10(43.5)$ & 8.3 & 25 \\
\hline
\end{tabular}

Abbreviations: $n$, number of cases; OS, overall survival; NHL, non-Hodgkin lymphoma; NOS, not otherwise specified; NR, not reached; DLBCL, diffuse large $\mathrm{B}$ cell lymphoma; SLL, small B cell lymphocytic lymphoma; MZL, marginal zone B cell lymphoma.

date of last follow-up. The estimated median follow-up was determined using the inverse Kaplan-Meier method. KaplanMeier curves and multivariable Cox model were built to analyze the OS and prognostic factors. I performed all statistical analyses by use of STATA, version 12 (STAT Corp, College Station, Texas, USA). All $p$ values were two-sided, and $p<0.05$ suggested statistical significance.

\section{Results}

\section{Clinical characteristics of all patients}

In the SEER database, between 1973 and 2012, there were 362,697 cases with lymphoma $(\mathrm{NHL}=312,459$; Hodgkin lymphoma $=50,238)$. Of the total $312,459 \mathrm{NHL}$ cases, there were 215,072 cases $(68.8 \%$ ) with nodal $\mathrm{NHL}$, and 97,387 cases with extranodal $\mathrm{NHL}(31.2 \%)$. Out of 97,387 cases with extranodal $\mathrm{NHL}$, there were 1,325 cases $(1.3 \%)$ with hepatic NHL. The final cohort included 785 cases with a first primary $\mathrm{NHL}$ of the liver (HEL) after applying my exclusion criteria (Fig. 1), that represented $0.25 \%$ of all NHLs. The clinical features of the 785 patients with HEL are presented in Table 1 . Of the 785 eligible cases, the median age at diagnosis was 61 years (range, 3-95 years) and 33.5\% were equal or older than 70 years. Most of the patients were male (64.2\%) and Whites (82.3\%).

\section{Histologic subtypes}

The clinical characteristics of the various subtypes of HEL are presented in Tables 1 and 2. According to lymphoma cell origin and clinical aggressiveness, there were $521(66.4 \%)$ cases of aggressive B cell NHLs, 59 (7.5\%) indolent B cell NHLs and 27 (3.4\%) T cell NHLs. The most common subtypes identified were DLBCL $(n=496,63.2 \%)$ and NHL-NOS ( $n=155,19.7 \%)$. The next most common subtypes were $\mathrm{T}$ cell lymphomas (3.4\%), Burkitt's lymphoma (3.2\%), follicular lymphoma (2.8\%), marginal zone B cell lymphoma (MZL) $(2.9 \%)$ and small B cell lymphocytic lymphoma (SLL) $(1.8 \%)$. The subtypes of T cell NHL were mature T cell lymphoma-NOS ( $n=16)$, anaplastic large cell lymphoma, T cell and null cell type $(n=9)$, NK/T cell lymphoma, nasal and nasal-type $(n=1)$, and precursor T cell lymphoblastic lymphoma $(n=1)$. All of the HEL subtypes were found more frequently in male patients, except for MZL $(47.8 \%)$ and follicular lymphoma $(40.9 \%)$. Although the median age for all patients was 61 years, Burkitt's lymphoma patients had a much younger median age (36 years; range, 5-87 years). The frequency of aggressive T cell NHLs was higher in Asians (8.7\%) and Blacks $(6.0 \%)$ than in Whites $(2.8 \%)$.

\section{Outcomes}

With a median follow-up of 87 months (95\%CI: 79 to 100 months), $474(60.4 \%)$ patients had died by the end of

Table 2. Patient characteristics by cell origin and tumor behavior

\begin{tabular}{llllll}
\hline Histology & $n(\%)$ & Median age, years (Range) & Male, $n(\%)$ & Death, $n(\%)$ & Median OS \\
\hline Aggressive B cell NHL $^{\text {a }}$ & $521(66.4)$ & $62(3-95)$ & $347(66.6)$ & $312(59.9)$ & 31.2 \\
Indolent B cell NHL $^{b}$ & $59(7.5)$ & $66(41-87)$ & $30(50.8)$ & $23(39.0)$ & 152.4 \\
T cell NHL & $27(3.4)$ & $52(25-90)$ & $21(77.8)$ & $16(59.3)$ & 8.3 \\
NHL-NOS & $155(19.7)$ & $58(11-91)$ & $96(61.9)$ & $105(67.7)$ & 21.2 \\
Others & $23(2.9)$ & $60(21-88)$ & $10(43.5)$ & $18(78.3)$ & 8.3 \\
\hline
\end{tabular}

Abbreviations: $n$, number of cases; OS, overall survival; NHL, non-Hodgkin lymphoma; NOS, not otherwise specified.

a Included diffuse large B cell lymphoma and Burkitt's lymphoma.

b Included follicular lymphoma, small B cell lymphocytic lymphoma and marginal zone B cell lymphoma. 
El-Fattah M.A.: Outcomes of hepatic non-Hodgkin lymphoma
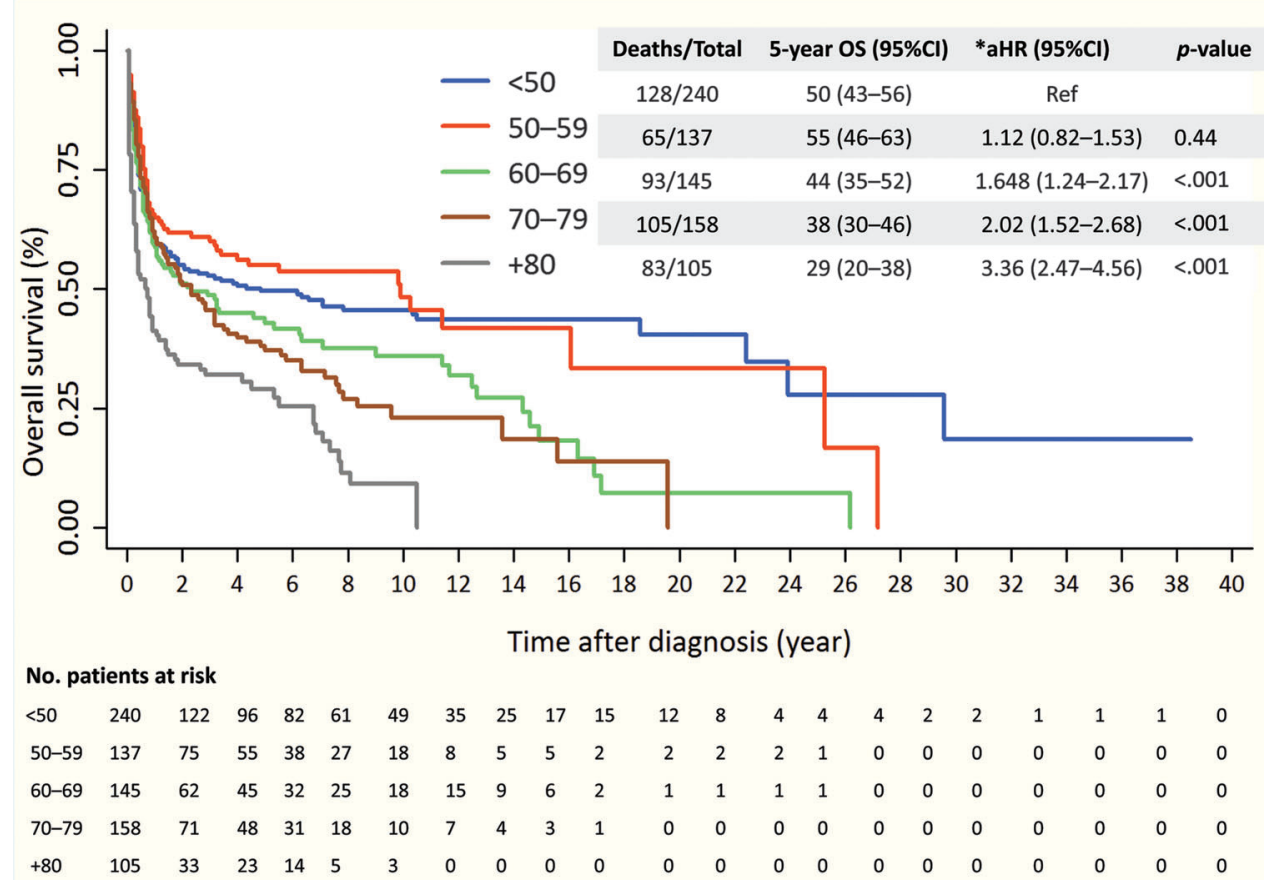

$\begin{array}{llllllllll}8 & 4 & 4 & 4 & 2 & 2 & 1 & 1 & 1 & 0 \\ 2 & 2 & 1 & 0 & 0 & 0 & 0 & 0 & 0 & 0 \\ 1 & 1 & 1 & 0 & 0 & 0 & 0 & 0 & 0 & 0 \\ 0 & 0 & 0 & 0 & 0 & 0 & 0 & 0 & 0 & 0 \\ 0 & 0 & 0 & 0 & 0 & 0 & 0 & 0 & 0 & 0\end{array}$

*Adjusted for gender, race, histologic subtypes, and Calendar period.

Fig. 2. Kaplan-Meier estimate of overall survival by age groups.

Abbreviations: OS, overall survival; $95 \% \mathrm{CI}$, confidence interval; aHR, adjusted hazard ratio.

study. Of which, 256 patients (54\%) died due to $\mathrm{NHL}$, and 80 patients $(16.9 \%)$ due to HIV-related complications. HIVrelated deaths accounted for $16.2 \%$ of deaths of DLBCL, and $40 \%$ of deaths of Burkitt's lymphoma (data not shown).

\section{Survival and prognostic variables}

For the entire cohort, with a median os of 33 months (95\% confidence interval [CI]: 22-48 months), the estimated 1-, 3-, $5-, 10-$ and 20 -year OS rates were 59\% (95\%CI: 56-62\%), $49 \%$ (95\% CI: 46-53\%), 44\% (95\%CI: 41-48), 35\% (95\% CI: $32-39 \%)$ and $21 \%(95 \% \mathrm{CI}: 15-27 \%)$, respectively. Compared to patients aged $<50$ years, the hazards of mortality of 60-69 years age group, 70-79 years age group and $\geq 80$ years age group were 1.61 -fold $(p<0.001), 1.8$-fold $(p<0.001)$ and 3.2 -fold $(p<0.001)$, respectively (Fig. 2$)$. Males had a shorter 5 -year OS than females ( $41 \%$ vs. $50 \%)$, and risk of death in males was $26 \%$ higher than in females (adjusted hazard ratio [aHR]: 1.26, 95\%CI: 1.03-1.54, $p=0.02$ ). The OS was lower in Blacks (aHR: $1.70,95 \% \mathrm{CI}$ : $1.26-2.29, p<0.001)$ and Asians (aHR: $1.57,95 \%$ CI: $1.10-$ 2.25, $p=0.01$ ) compared with White patients (Table 3, Fig. 3).

The estimated 5-year OS rates during the periods of 1973-1995, 1996-2000, 2001-2005 and 2006-2012 were $33 \%$ (95\%CI: $26-41 \%)$, 35\% (95\%CI: $26-44 \%)$, 50\% (95\%CI: $43-57 \%)$ and 50\% (95\%CI: 44-56\%), respectively $(p<0.001)$. The median OS of patients with HEL improved from 19 months when diagnosed in the period of 1996-2000 to 60 months when diagnosed between 2006 and $2012(p<0.001)$ (Table 3, Fig. 4).
The OS rates for the various subtypes of HEL are shown in Table 1 and Fig. 5. The 5-year OS for indolent B cell NHLs was $62 \%$ (95\%CI: $47-74 \%$ ), as compared with $44 \%$ (95\%CI: $39-48 \%$ ) for aggressive B cell NHLs and $42 \%$ (95\%CI: $23-60 \%$ ) for T cell NHLs. The best 5 -year OS rates were observed for follicular lymphoma (84\%), MZL (60\%) and Burkitt's lymphoma (55\%). The 5-year OS of DLBCL was $43 \%$, which was comparable to SLL (42\%) and T cell NHL (42\%).

Table 3 details the multivariable Cox regression analysis of the $785 \mathrm{HEL}$ patients in which age of $\geq 80$ years (aHR: 3.21 , $p<0.001$ ), male sex (aHR: $1.26, p=0.02$ ), Black race (aHR: $1.70, p<0.001$ ), and T cell NHL histologic subtype (aHR: $1.73, p=0.03$ ) were unfavorable prognostic factors. The risk of all-cause mortality for patients diagnosed in the periods of 2001-2005 and 2006-2012 were 40\% and 43\% lower than those diagnosed in the period of 1973-1995 (all, $p<0.001)$.

\section{Discussion}

PHL is defined according to Caccamo's criteria ${ }^{34}$ as lymphoma with only liver involvement at presentation. Although, some have accepted cases as being primary, describing predominant liver involvement, even with the presence of extrahepatic disease. ${ }^{3,29,31}$

Over a long period of time, I found 785 cases with a first primary NHL of the liver were recorded in the US National Cancer Institute database (1973 to 2012), without a history of prior or concurrent cancer diagnosis. This study represents the largest evaluation of hepatic lymphoma to date. I observed that HEL accounted for $0.25 \%$ of all NHLs, which accords with 
El-Fattah M.A.: Outcomes of hepatic non-Hodgkin lymphoma

Table 3. Clinical features, outcomes and prognostic factors of non-Hodgkin lymphoma of the liver

\begin{tabular}{|c|c|c|c|c|}
\hline \multirow[b]{2}{*}{ Variables } & \multirow[b]{2}{*}{ n (\%) } & \multirow{2}{*}{$\begin{array}{l}\text { Median OS } \\
\text { in months }\end{array}$} & \multicolumn{2}{|l|}{ Multivariate analysis } \\
\hline & & & Hazard ratio $(95 \% \mathrm{CI})$ & $p$-value \\
\hline All patients & $785(100.0)$ & 33.0 & & \\
\hline \multicolumn{5}{|l|}{ Age in years } \\
\hline$<50$ & $240(30.6)$ & 58.0 & Ref & \\
\hline $50-59$ & $137(17.5)$ & 119.3 & $1.10(0.81-1.50)$ & 0.53 \\
\hline $60-69$ & $145(18.5)$ & 28.3 & $1.61(1.22-2.13)$ & $<0.001$ \\
\hline $70-79$ & $158(20.1)$ & 28.3 & $1.88(1.43-2.48)$ & $<0.001$ \\
\hline+80 & $105(13.4)$ & 9.02 & $3.21(2.37-4.35)$ & $<0.001$ \\
\hline \multicolumn{5}{|l|}{ Sex } \\
\hline Female & $281(35.8)$ & 60.1 & Ref & \\
\hline Male & $504(64.2)$ & 24.4 & $1.26(1.03-1.54)$ & 0.02 \\
\hline \multicolumn{5}{|l|}{ Race } \\
\hline White & $646(82.3)$ & 39.3 & Ref & \\
\hline Black & $83(10.6)$ & 11.9 & $1.70(1.26-2.29)$ & $<.001$ \\
\hline Asian & $46(5.9)$ & 6.9 & $1.57(1.10-2.25)$ & 0.01 \\
\hline Others $^{a}$ & $10(1.3)$ & 66.1 & $0.97(0.43-2.19)$ & 0.94 \\
\hline \multicolumn{5}{|l|}{ NHL subtypes } \\
\hline Aggressive $\mathrm{B}$ cell $\mathrm{NHL}^{\mathrm{b}}$ & $521(66.4)$ & 31.2 & Ref & \\
\hline Indolent $\mathrm{B}$ cell $\mathrm{NHL}^{\mathrm{c}}$ & $59(7.5)$ & 152.4 & $0.50(0.32-0.77)$ & 0.001 \\
\hline T cell NHL & $27(3.4)$ & 8.3 & $1.73(1.04-2.89)$ & 0.03 \\
\hline NHL-NOS & 155 (19.7) & 21.2 & $0.97(0.77-1.22)$ & 0.82 \\
\hline Others & $23(2.9)$ & 8.3 & $1.25(0.76-2.06)$ & 0.36 \\
\hline \multicolumn{5}{|l|}{ Calendar period } \\
\hline 1973-1995 & 145 (18.5) & 10.1 & Ref & \\
\hline 1996-2000 & $108(13.8)$ & 19.0 & $0.90(0.67-1.21)$ & 0.50 \\
\hline $2001-2005$ & $196(25.0)$ & 48.9 & $0.60(0.46-0.80)$ & $<.001$ \\
\hline $2006-2012$ & $336(42.8)$ & 60.0 & $0.57(0.44-0.75)$ & $<.001$ \\
\hline
\end{tabular}

Abbreviations: $n$, number of cases; NOS, not otherwise specified; OS, overall survival; CI, confidence interval.

${ }_{\text {a American Indian/Alaska Native, unknown. }}$

${ }^{b}$ Included diffuse large B-cell lymphoma and Burkitt's lymphoma.

${ }^{\mathrm{C}}$ Included follicular lymphoma, small B cell lymphocytic lymphoma and marginal zone B cell lymphoma.

the previous Western ${ }^{6}$ and Asian reports. ${ }^{25,35}$ The median age at diagnosis was 61 years (range, 3-95 years), which was slightly older than the literature (50 to 56 years), ${ }^{6,9,29}$ with a male-to-female ratio of $1.8: 1$.

DLBCL comprises $33 \%$ of all $\mathrm{NHL}^{36}$ and $46 \%$ to $96 \%$ of PHL cases. $6,9,10,14$ Hepatic DLBCL accounted for approximately $6 \%$ of all primary extranodal DLBCL. ${ }^{37}$ My analysis revealed that B cell $\mathrm{NHL}$ accounted for approximately $74 \%$ all hepatic NHLs, and the most common histopathological diagnosis was DLBCL, which was observed in 496 (63.2\%) cases. In a retrospective review of 31 patients with $\mathrm{PHL}$ collected from 55 French hospitals, 22 cases (71\%) had DLBCL. ${ }^{9}$ Immunophenotyping analysis of $59 \mathrm{PHL}$ cases; most were of B cell lineage ( 37 cases, $63 \%$ ) and 15 were T cell (25\%). ${ }^{18}$

In the current study, the frequency of T-cell NHL is low (3.4\%) compared to previous reports $(5-10 \%){ }^{3}$ The most observed hepatic T cell NHLs were mature T cell lymphomaNOS (59.3\%) and anaplastic large cell lymphoma T cell/null cell type $(33.3 \%)$. In literature, the described subtypes of $\mathrm{T}$ cell lymphoma of the liver include peripheral $\mathrm{T}$ cell lymphoma, ${ }^{26}$ anaplastic $T$ cell lymphoma ${ }^{31}$ and hepatosplenic $\mathrm{T}$ cell lymphoma. The frequency of aggressive T cell NHLs increased in Asians (8.7\%) and Blacks (6.0\%), as compared to Whites $(2.8 \%)$. This may, in part, reflect increased exposure to pathogenic factors, such as human $T$ cell leukemia virus-1 (HTLV-1) and EBV in Asian and African nations. ${ }^{27,38,39}$

I observed that the 5 -year OS of hepatic DLBCL was $44 \%$, which was comparable to the Japanese report (43\%). ${ }^{25}$ In addition, the risk of mortality for hepatic T cell NHL cases was $73 \%$ higher than those with an aggressive $\mathrm{B}$ cell $\mathrm{NHL}$ of the liver (HR: 1.73, $p=0.03$ ). Notably, many patients with primary hepatic $\mathrm{T}$ cell lymphoma present with aggressive diffuse liver infiltration. ${ }^{40}$

Hepatic marginal zone B cell lymphoma of mucosaassociated lymphoid tissue (MALT) lymphomas are reported to occur in $2-4 \%$ of cases of hepatic malignant lymphoma, $6,9,29$ 
El-Fattah M.A.: Outcomes of hepatic non-Hodgkin lymphoma

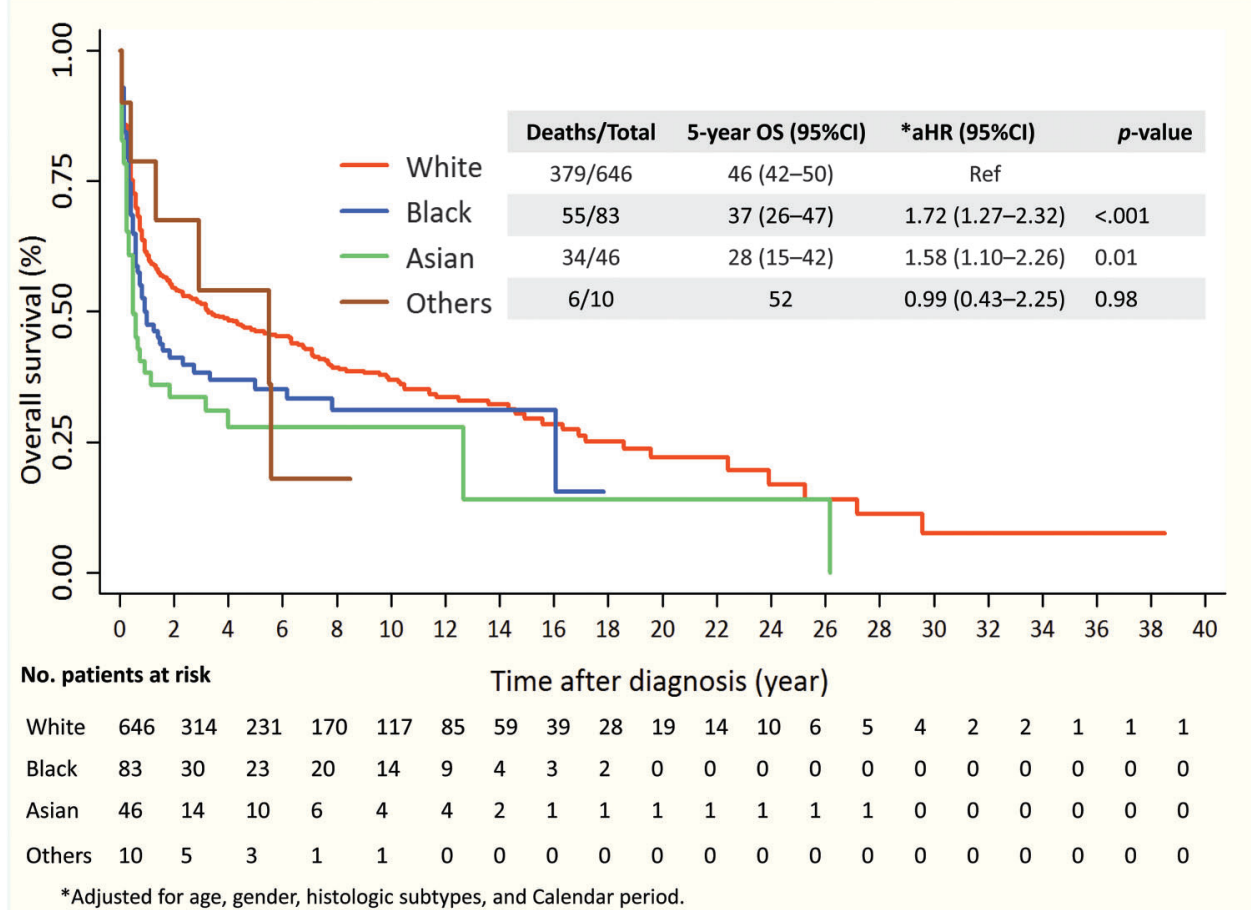

Fig. 3. Kaplan-Meier estimate of overall survival by race.

Abbreviations: OS, overall survival; 95\%CI, confidence interval; aHR, adjusted hazard ratio.

as a result of chronic antigenic simulation. ${ }^{41}$ Most PHL in patients with primary biliary cirrhosis is low-grade MALT Iymphoma. ${ }^{3}$ A quarter of primary hepatic MALT lymphomas are HCV sero-positive, $^{25}$ and spontaneous remission has been reported. ${ }^{9}$ To date, only 46 cases with primary hepatic MALT lymphoma have been reported and $35.5 \%$ had a pre-existing

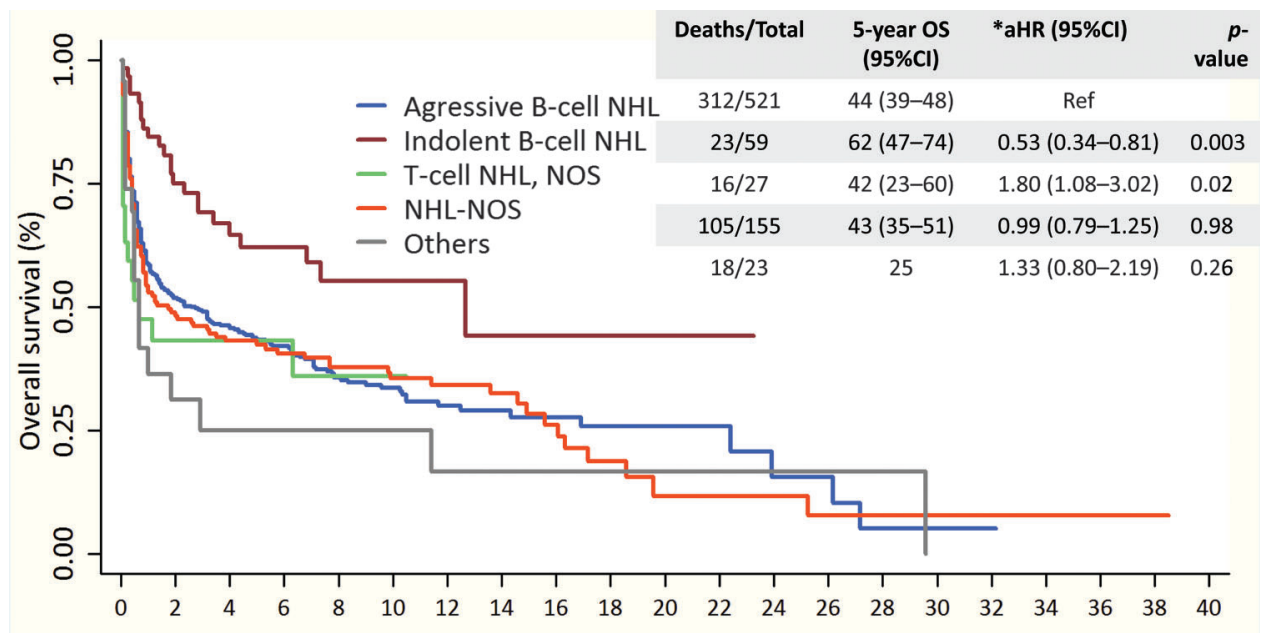

No. patients at risk

Time after diagnosis (year)

$\begin{array}{llllllllllllllllllll}-521 & 236 & 170 & 118 & 78 & 52 & 33 & 22 & 16 & 11 & 10 & 6 & 3 & 3 & 1 & 1 & 1 & 0 & 0 & 0 \\ -59 & 39 & 28 & 22 & 14 & 9 & 7 & 2 & 2 & 2 & 1 & 1 & 0 & 0 & 0 & 0 & 0 & 0 & 0 & 0 \\ -27 & 10 & 8 & 6 & 3 & 2 & 0 & 0 & 0 & 0 & 0 & 0 & 0 & 0 & 0 & 0 & 0 & 0 & 0 & 0 \\ -155 & 72 & 57 & 47 & 38 & 32 & 23 & 18 & 12 & 6 & 3 & 3 & 3 & 2 & 2 & 1 & 1 & 1 & 1 & 1 \\ & \\ 23 & 6 & 4 & 4 & 3 & 3 & 2 & 1 & 1 & 1 & 1 & 1 & 1 & 1 & 1 & 0 & 0 & 0 & 0 & 0 \\ & \text { *Adjusted for age, gender, race, and Calendar period. }\end{array}$

Fig. 4. Kaplan-Meier estimate of overall survival by calendar year of diagnosis.

Abbreviations: OS, overall survival; $95 \% \mathrm{CI}$, confidence interval; aHR, adjusted hazard ratio. 


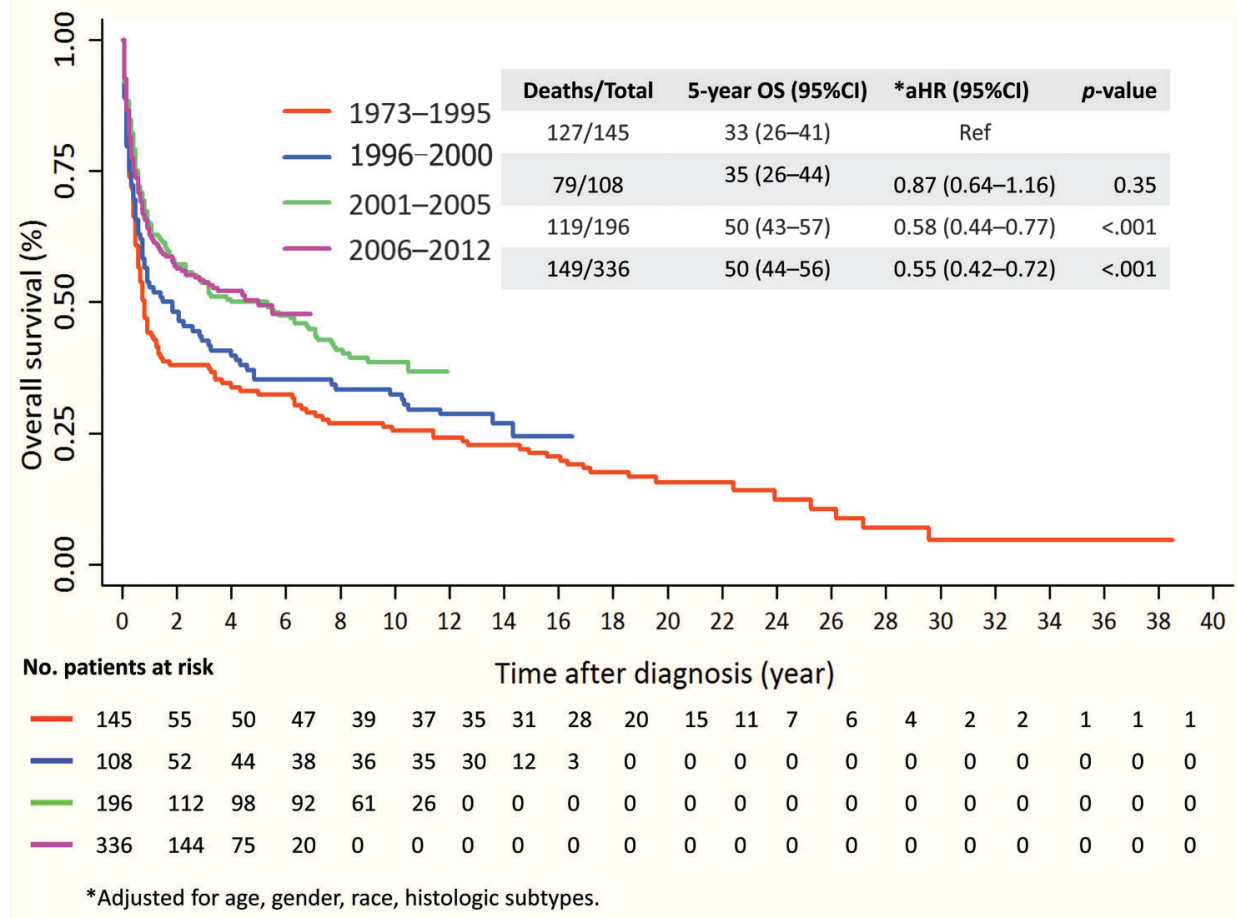

Fig. 5. Kaplan-Meier estimate of overall survival by cell origin and tumor behavior.

Abbreviations: NHL, non-Hodgkin lymphoma; NOS, not otherwise specified; OS, overall survival; 95\%CI, confidence interval; aHR, adjusted hazard ratio.

liver disease. ${ }^{30}$ In the present study, hepatic MZL accounted for about $3 \%$ of all cases, with a long 5 -year OS (60\%) and median OS (82.9 months), comparable to the 84 months reported in 8 primary hepatic MALT Iymphoma cases in Japan. ${ }^{25}$ In a review of 18 hepatic MALT lymphoma cases, median OS was 65 months. $^{25}$

Follicular lymphoma accounted for less than $4 \%$ of PHL. ${ }^{9,29}$ In our study, the 5 -year OS rate of hepatic follicular lymphoma was $84 \%$, which was comparable to the 5 -year OS for population of follicular lymphoma ( $52 \%$ to $90 \%){ }^{42}$ I observed that the hepatic Burkitt's lymphoma has a slight predominance in females, with 5 -year OS of $55 \%$ compared to $23 \%$ to $71 \%$ in a previous report. ${ }^{43}$ In addition, $40 \%$ of deaths in hepatic Burkitt's lymphoma were related to HIVrelated complications. Of note, primary hepatic Burkitt's lymphoma had been reported in concurrent viral infection, such as HIV, ${ }^{44,45} \mathrm{HCV}^{46}$ and HBV. ${ }^{47}$ Anti-HIV therapy has no significant impact on outcomes of HIV-Burkitt's lymphoma ${ }^{48}$ compared to some HIV-related lymphomas, such as primary effusion lymphoma. ${ }^{49}$ In addition, direct-acting antivirals could be promising in HCV-associated indolent B cell NHL. ${ }^{50}$

In the current study, 474 patients $(60.4 \%)$ had died by end of study. Of which, 256 patients ( $54 \%$ ) died due to $\mathrm{NHL}$, and 80 patients $(16.9 \%)$ due to HIV-related complications. HIV was reported in $40 \%$ to $75 \%$ of PHL cases. ${ }^{10,14}$ In a single centre study, after a median follow-up of 19 months for 22 hepatic lymphoma cases, 12 patients $(54.5 \%)$ had died. ${ }^{14}$ Most patients with PHL present with poor prognostic features, such as advanced age, constitutional symptoms, bulky disease, unfavorable histologic subtypes, elevated lactate dehydrogenase, and co-morbidities (cirrhosis, chronic active hepatitis, HIV, immunosuppression, etc.). ${ }^{6,7}$
Patients with $\mathrm{PHL}$ have a favorable survival compared to those with hepatic involvement of systemic lymphoma, ${ }^{25,32}$ but this issue is controversial. ${ }^{10}$ In the entire cohort, the median OS was 33 months (95\%CI: 21-48 months) and the 5 -year OS rate was $44 \%$ (95\%CI: $41-48 \%)$. In the literature, the median survival of PHL cases ranged from 4 to 30 months, $6,18,29,51$ rising to 60 months in patients who received combined triple-modalities (surgical resection and chemo-radiotherapy). ${ }^{29}$ The poorest 5 -year OS rates were observed for aggressive B cell NHLs (44\%, 95\%CI: 39-48\%) and $\mathrm{T}$ cell NHLs $(42 \%, 95 \% \mathrm{CI}: 32-60 \%)$. In the Japanese series of $10 \mathrm{PHL}$ cases treated with combined chemotherapy ( 5 of who received rituximab), the median OS was 27 months, and the 5 -year OS rate was $44 \% .{ }^{25}$ The 20 -year experience with PHL at the MD Anderson Cancer Center (1974-1995) showed a 5 -year OS of $83 \% .^{6}$ The pattern of tumor infiltration had an impact on clinical outcomes. ${ }^{11}$ In a review of 62 cases, the 3-year OS in nodular PHL was 57\%, and in diffuse PHL was $18 \%,{ }^{11}$ versus $49 \%$ (95\%CI: $\left.46-53 \%\right)$ in our analysis.

In the current study, the mortality risk increased remarkably with advancing age. In addition, the risk of deaths in males was $26 \%$ higher than in females (aHR: $1.26,95 \% \mathrm{CI}$ : 1.03-1.54). It seems that the poor performance status, rather than advanced age, has negative impact on the outcome of $\mathrm{NHL}^{52}$ and lymphoma presenting as acute liver failure was seen twice as often in men as it was in women. ${ }^{21}$ Furthermore, the male predominance is striking in lymphomas of T cell origin. ${ }^{12}$

I noted that the survival rates were lower in Blacks (aHR: $1.70, p<0.001$ ) and Asians (aHR: $1.57, p=0.01$ ) compared with White patients. Notably, Asian patients tended to have aggressive PHL subtypes (i.e. T cell NHL) with diffuse tumor 
infiltration. ${ }^{51}$ Furthermore, chronic liver disease before the onset of hepatic lymphoma was reported in $44 \%$ of Japanese cases compared to only $9.6 \%$ of Western cases. ${ }^{17,53}$ Regarding the year of diagnosis, the survival improved in the most recent calendar period (2001-2012), and new drugs such as Rituximab may have played a major role. ${ }^{54}$ Rituximab is an anti-CD20 monoclonal antibody, FDA approved in 1997 for the treatment of relapsed or refractory indolent $B$ cell lymphomas, and then in 2006 approved as a frontline therapy for patients with diffuse large B cell or follicular B cell NHL.

There are several limitations to the present study. The SEER database provides no information regarding whether chemo-immunotherapy was administered. In addition, no data regarding the pattern of liver infiltration and viral status are provided. Although this analysis was restricted, the extranodal NHL affects liver diagnosed by pathology, with no history of prior, or a concurrent cancer diagnosis. Actually, I could not meet the strict criteria for PHL suggested by Caccamo et al., ${ }^{34}$ and some cases were not actually PHL, and were cases of secondary liver involvement with extrahepatic disease. However, no standard diagnostic criteria of PHL exist, and some have accepted cases as being primary, describing predominant liver involvement, even with the presence of extrahepatic disease. ${ }^{3,31}$

\section{Conclusions}

In the USA, over a long period of time, first primary $\mathrm{NHL}$ of the liver has accounted for about $0.3 \%$ of all NHLs. The most common histological variant was DLBCL (63.2\%). It appears that the survival of patients with hepatic $\mathrm{NHL}$ has improved since 2000. This could reflect the more frequent use of novel agents, such as with rituximab as upfront management of NHLs. Asian and Black patients had more frequent aggressive T cell NHL with poor outcomes, which could be related to an endemic viral infection, such as with HTLV-1 or EBV.

\section{Conflict of interest}

The author has no conflict of interest related to this publication.

\section{Author contributions}

Designed the study, performed the data analysis and interpretations, and wrote the manuscript (MAE).

\section{References}

[1] Zelenetz AD, Abramson JS, Advani RH, Andreadis CB, Byrd JC, Czuczman MS, et al. NCCN Clinical Practice Guidelines in Oncology: non-Hodgkin's lymphomas. J Natl Compr Canc Netw 2010;8:288-334. doi: 10.6004/jnccn.2010. 0021.

[2] Krol AD, le Cessie S, Snijder S, Kluin-Nelemans JC, Kluin PM, Noordijk EM. Primary extranodal non-Hodgkin's lymphoma (NHL): the impact of alternative definitions tested in the Comprehensive Cancer Centre West population-based NHL registry. Ann Oncol 2003;14:131-139. doi: 10.1093/ annonc/mdg004.

[3] Salmon JS, Thompson MA, Arildsen RC, Greer JP. Non-Hodgkin's lymphoma involving the liver: clinical and therapeutic considerations. Clin Lymphoma Myeloma 2006;6:273-280. doi: 10.3816/CLM.2006.n.001.

[4] Civardi G, Vallisa D, Bertè R, Lazzaro A, Moroni CF, Cavanna L. Focal liver lesions in non-Hodgkin's lymphoma: investigation of their prevalence, clinical significance and the role of Hepatitis C virus infection. Eur J Cancer 2002; 38:2382-2387. doi: 10.1016/S0959-8049(02)00481-1.

[5] Aozasa K, Mishima K, Ohsawa M. Primary malignant lymphoma of the liver. Leuk Lymphoma 1993;10:353-357. doi: 10.3109/10428199309148560.
[6] Page RD, Romaguera JE, Osborne B, Medeiros LJ, Rodriguez J, North L, et al. Primary hepatic lymphoma: favorable outcome after combination chemotherapy. Cancer 2001;92:2023-2029. doi: 10.1002/1097-0142 (20011015)92:8<2023: :AID-CNCR1540>3.0.CO;2-B.

[7] Noronha V, Shafi NQ, Obando JA, Kummar S. Primary non-Hodgkin's lymphoma of the liver. Crit Rev Oncol Hematol 2005;53:199-207. doi: 10. 1016/j.critrevonc.2004.10.010.

[8] Santos ES, Raez LE, Salvatierra J, Morgensztern D, Shanmugan N, Neff GW. Primary hepatic non-Hodgkin's lymphomas: case report and review of the literature. Am J Gastroenterol 2003;98:2789-2793. doi: 10.1111/j.15720241.2003.08766.x.

[9] Bronowicki JP, Bineau C, Feugier P, Hermine O, Brousse N, Oberti F, et al. Primary lymphoma of the liver: clinical-pathological features and relationship with HCV infection in French patients. Hepatology 2003;37:781-787.doi: 10. 1053/jhep.2003.50121.

[10] Swadley MJ, Deliu M, Mosunjac MB, Gunthel CJ, Nguyen ML, Hanley KZ. Primary and secondary hepatic lymphomas diagnosed by image-guided fine-needle aspiration: a retrospective study of clinical and cytomorphologic findings. Am J Clin Pathol 2014;141:119-127. doi: 10.1309/AJCPE58ESCQDZFKX.

[11] Emile JF, Azoulay D, Gornet JM, Lopes G, Delvart V, Samuel D, et al. Primary non-Hodgkin's lymphomas of the liver with nodular and diffuse infiltration patterns have different prognoses. Ann Oncol 2001;12:1005-1010. doi: 10. 1023/A:1011131930409.

[12] Loddenkemper C, Longerich T, Hummel M, Ernestus K, Anagnostopoulos I, Dienes HP, et al. Frequency and diagnostic patterns of lymphomas in liver biopsies with respect to the WHO classification. Virchows Arch 2007;450: 493-502. doi: 10.1007/s00428-007-0384-9.

[13] De Renzo A, Perna F, Persico M, Notaro R, Mainolfi C, de Sio I, et al. Excellent prognosis and prevalence of HCV infection of primary hepatic and splenic non-Hodgkin's lymphoma. Eur J Haematol 2008;81:51-57. doi: 10.1111/j. 1600-0609.2008.01081.x.

[14] El-Sharkawi D, Ramsay A, Cwynarski K, Hughes D, Prentice A, Davies N, et al. Clinico-pathologic characteristics of patients with hepatic lymphoma diagnosed using image-guided liver biopsy techniques. Leuk Lymphoma 2011;52:2130-2134. doi: 10.3109/10428194.2011.589546.

[15] Kim JH, Kim HY, Kang I, Kim YB, Park CK, Yoo JY, et al. A case of primary hepatic lymphoma with hepatitis C liver cirrhosis. Am J Gastroenterol 2000; 95:2377-2380. doi: 10.1111/j.1572-0241.2000.02278.x.

[16] Iannitto E, Ammatuna E, Tripodo C, Marino C, Calvaruso G, Florena AM, et al. Long-lasting remission of primary hepatic lymphoma and hepatitis $C$ virus infection achieved by the alpha-interferon treatment. Hematol J 2004;5: 530-533. doi: 10.1038/sj.thj.6200408.

[17] Higuchi T, Nomoto K, Mori H, Niikura H, Omine M, Sekiyama K, et al. Case report: primary hepatic lymphoma associated with chronic liver disease. J Gastroenterol Hepatol 1997;12:237-242. doi: 10.1111/j.1440-1746. 1997.tb00415.x.

[18] Avlonitis VS, Linos D. Primary hepatic lymphoma: a review. Eur J Surg 1999; 165:725-729. doi: 10.1080/11024159950189474.

[19] Rowbotham D, Wendon J, Williams R. Acute liver failure secondary to hepatic infiltration: a single centre experience of 18 cases. Gut 1998;42:576-580. doi: $10.1136 /$ gut.42.4.576

[20] Cameron AM, Truty J, Truell J, Lassman C, Zimmerman MA, Kelly BS Jr, et al. Fulminant hepatic failure from primary hepatic lymphoma: successful treatment with orthotopic liver transplantation and chemotherapy. Transplantation 2005;80:993-996. doi: 10.1097/01.TP.0000173999.09381.95.

[21] Lettieri CJ, Berg BW. Clinical features of non-Hodgkins lymphoma presenting with acute liver failure: a report of five cases and review of published experience. Am J Gastroenterol 2003;98:1641-1646. doi: 10.1111/j.15720241.2003.07536.x.

[22] Seymour JF, Gagel RF, Hagemeister FB, Dimopoulos MA, Cabanillas F. Calcitriol production in hypercalcemic and normocalcemic patients with nonHodgkin lymphoma. Ann Intern Med 1994;121:633-640. doi: 10.7326/ 0003-4819-121-9-199411010-00001.

[23] Maher MM, McDermott SR, Fenlon HM, Conroy D, O'Keane JC, Carney DN, et al. Imaging of primary non-Hodgkin's lymphoma of the liver. Clin Radiol 2001;56:295-301. doi: 10.1053/crad.2000.0649.

[24] Rizzi EB, Schinina V, Cristofaro M, David V, Bibbolino C. Non-hodgkin's lymphoma of the liver in patients with AIDS: sonographic, CT, and MRI findings. J Clin Ultrasound 2001;29:125-129. doi: 10.1002/1097-0096(200103/04) 29:3<125: :AID-JCU1011>3.0.CO;2-Y.

[25] Kikuma K, Watanabe J, Oshiro Y, Shimogama T, Honda Y, Okamura S, et al. Etiological factors in primary hepatic B-cell lymphoma. Virchows Arch 2012; 460:379-387. doi: 10.1007/s00428-012-1199-x.

[26] Stancu M, Jones D, Vega F, Medeiros LJ. Peripheral T-cell lymphoma arising in the liver. Am J Clin Pathol 2002;118:574-581. doi: 10.1309/9DAQ-PWP3XKDG-CUTG.

[27] Eom DW, Huh JR, Kang YK, Lee YS, Yu E. Clinicopathological features of eight Korean cases of primary hepatic lymphoma. Pathol Int 2004;54:830-836. doi: $10.1111 / j .1440-1827.2004 .01752 . x$. 
[28] El-Fattah MA. Hepatocellular carcinoma biology predicts survival outcome after liver transplantation in the USA. Indian J Gastroenterol 2017. doi: 10. 1007/s12664-017-0732-x.

[29] Lei KI. Primary non-Hodgkin's lymphoma of the liver. Leuk Lymphoma 1998; 29:293-299. doi: 10.3109/10428199809068566.

[30] Murakami J, Fukushima N, Ueno H, Saito T, Watanabe T, Tanosaki R, et al. Primary hepatic low-grade B-cell lymphoma of the mucosa-associated lymphoid tissue type: a case report and review of the literature. Int $\mathrm{J}$ Hematol 2002;75:85-90. doi: 10.1007/BF02981985.

[31] Baschinsky DY, Weidner N, Baker PB, Frankel WL. Primary hepatic anaplastic large-cell lymphoma of T-cell phenotype in acquired immunodeficiency syndrome: a report of an autopsy case and review of the literature. Am J Gastroenterol 2001;96:227-232. doi: 10.1111/j.1572-0241.2001.03481.x.

[32] Peng Y, Qing AC, Cai J, Yue C, French SW, Qing X. Lymphoma of the liver: Clinicopathological features of 19 patients. Exp Mol Pathol 2016;100: 276-280. doi: 10.1016/j.yexmp.2016.02.001.

[33] O'Neill BP, Decker PA, Tieu C, Cerhan JR. The changing incidence of primary central nervous system lymphoma is driven primarily by the changing incidence in young and middle-aged men and differs from time trends in systemic diffuse large B-cell non-Hodgkin's lymphoma. Am J Hematol 2013;88: 997-1000. doi: 10.1002/ajh.23551.

[34] Caccamo D, Pervez NK, Marchevsky A. Primary lymphoma of the liver in the acquired immunodeficiency syndrome. Arch Pathol Lab Med 1986;110: 553-555.

[35] Ma YJ, Chen EQ, Chen XB, Wang J, Tang H. Primary hepatic diffuse large B cell lymphoma: A case report: Primary hepatic diffuse large B cell lymphoma. Hepat Mon 2011;11:203-205.

[36] Møller MB, Pedersen NT, Christensen BE. Diffuse large B-cell lymphoma: clinical implications of extranodal versus nodal presentation-a populationbased study of 1575 cases. Br J Haematol 2004;124:151-159. doi: 10. 1046/j.1365-2141.2003.04749.x.

[37] López-Guillermo A, Colomo L, Jiménez M, Bosch F, Villamor N, Arenillas L, et al. Diffuse large B-cell lymphoma: clinical and biological characterization and outcome according to the nodal or extranodal primary origin. J Clin Oncol 2005;23:2797-2804. doi: 10.1200/JCO.2005.07.155

[38] Rizvi MA, Evens AM, Tallman MS, Nelson BP, Rosen ST. T-cell non-Hodgkin lymphoma. Blood 2006;107:1255-1264. doi: 10.1182/blood-2005-03-1306.

[39] Arisawa K, Soda M, Endo S, Kurokawa K, Katamine S, Shimokawa I, et al. Evaluation of adult T-cell leukemia/lymphoma incidence and its impact on non-Hodgkin lymphoma incidence in southwestern Japan. Int J Cancer 2000; 85:319-324. doi: 10.1002/(SICI)1097-0215(20000201)85:3<319::AIDIJC4>3.0.CO;2-B.

[40] Miyashita $\mathrm{K}$, Tomita $\mathrm{N}$, Oshiro $\mathrm{H}$, Matsumoto $\mathrm{C}$, Nakajima $\mathrm{Y}$, Ito $\mathrm{S}$, et al. Primary hepatic peripheral T-cell lymphoma treated with corticosteroid. Intern Med 2011;50:617-620. doi: 10.2169/internalmedicine.50.4686

[41] Ye MQ, Suriawinata A, Black C, Min AD, Strauchen J, Thung SN. Primary hepatic marginal zone B-cell lymphoma of mucosa-associated lymphoid tissue type in a patient with primary biliary cirrhosis. Arch Pathol Lab Med 2000;124:604-608. doi: 10.1043/0003-9985(2000)124<0604: PHMZBC>2.0.CO;2.

[42] Solal-Céligny P, Roy $P$, Colombat $P$, White J, Armitage JO, Arranz-Saez R, et al. Follicular lymphoma international prognostic index. Blood 2004;104: 1258-1265. doi: 10.1182/blood-2003-12-4434.

[43] Smeland S, Blystad AK, Kvaløy SO, Ikonomou IM, Delabie J, Kvalheim G, et al. Treatment of Burkitt's/Burkitt-like lymphoma in adolescents and adults: a 20-year experience from the Norwegian Radium Hospital with the use of three successive regimens. Ann Oncol 2004;15:1072-1078. doi: 10.1093/annonc/ $\operatorname{mdh} 262$.

[44] Mattar WE, Alex BK, Sherker AH. Primary hepatic burkitt lymphoma presenting with acute liver failure. J Gastrointest Cancer 2010;41:261-263. doi: 10. 1007/s12029-010-9150-3.

[45] Jacobs SL, Rozenblit A. HIV-associated hypervascular primary Burkitt's lymphoma of the liver. Clin Radiol 2006;61:453-455. doi: 10.1016/j.crad.2005. 12.007.

[46] Kuroda J, Omoto A, Fujiki H, Okugawa K, Tamai H, Yamagishi H, et al. Primary hepatic Burkitt's lymphoma with chronic hepatitis C. Acta Haematol 2001:105:237-240. doi: 10.1159/000046571.

[47] Lee $\mathrm{SH}$, Kim HJ, Mun JS, Oh HC, Lee HW, Choi CH, et al. A case of primary hepatic Burkitt's lymphoma. Korean J Gastroenterol 2008;51:259-264.

[48] Lim ST, Karim R, Nathwani BN, Tulpule A, Espina B, Levine AM. AIDS-related Burkitt's lymphoma versus diffuse large-cell lymphoma in the pre-highly active antiretroviral therapy (HAART) and HAART eras: significant differences in survival with standard chemotherapy. J Clin Oncol 2005;23:4430-4438. doi: $10.1200 /$ JCO.2005.11.973.

[49] El-Fattah MA. Clinical characteristics and survival outcome of primary effusion Iymphoma: A review of 105 patients. Hematol Oncol 2016. doi: 10. 1002/hon.2372.

[50] Arcaini L, Besson C, Frigeni M, Fontaine H, Goldaniga M, Casato M, et al. Interferon-free antiviral treatment in B-cell lymphoproliferative disorders associated with hepatitis C virus infection. Blood 2016;128:2527-2532. doi: 10.1182/blood-2016-05-714667.

[51] Lei KI, Chow JH, Johnson PJ. Aggressive primary hepatic lymphoma in Chinese patients. Presentation, pathologic features, and outcome. Cancer 1995;76:1336-1343. doi: 10.1002/1097-0142(19951015)76:8<1336:: AID-CNCR2820760807>3.0.CO;2-I.

[52] Gómez H, Hidalgo M, Casanova L, Colomer R, Pen DL, Otero J, et al. Risk factors for treatment-related death in elderly patients with aggressive nonHodgkin's lymphoma: results of a multivariate analysis. J Clin Oncol 1998; 16:2065-2069. doi: 10.1200/JCO.1998.16.6.2065.

[53] Ohsawa M, Aozasa K, Horiuchi K, Kataoka M, Hida J, Shimada H, et al. Malignant lymphoma of the liver. Report of five cases and review of the literature. Dig Dis Sci 1992;37:1105-1109. doi: 10.1007/BF01300294.

[54] Coiffier B, Lepage E, Briere J, Herbrecht R, Tilly H, Bouabdallah R, et al. CHOP chemotherapy plus rituximab compared with CHOP alone in elderly patients with diffuse large-B-cell lymphoma. N Engl J Med 2002;346:235-242. doi: 10.1056/NEJMoa011795. 